\title{
Cuerpo e imagen. Hacia un desajuste de la sensación en la estética de Gilles Deleuze
}

\author{
Body and image. Towards a sensation mismatch in Gilles \\ Deleuze's aesthetics
}

Corpo e imagem. Em direção a um desajuste da sensação na estética de Gilles Deleuze

\section{Prof. Nicolás Perrone*}

\begin{abstract}
RESUMEN
La filosofía del arte de Deleuze presta atención a los diversos modos en que se quiebra la lógica de la representación. Sus análisis sobre ciertas prácticas artísticas funcionan como un aparato crítico del esencialismo. En este trabajo nos interesa ver cómo la problematización de la corporalidad es parte del esfuerzo deleuziano de superación de la representación. Esto se traduce en una particular lógica de la sensación, dentro de la cual no se puede construir estratos cerrados ni reducidos a formas identitarias. Por el contrario, la sensación está desajustada en la medida en que circulan fuerzas que actúan sobre los cuerpos y los transforman constantemente. Para comprender tal desviación, nos proponemos analizar conceptos como "cuerpo sin órganos", "haecceidad" y "devenir minoritario", y observar cómo algunas prácticas artísticas hacen operar esas nociones en el marco de un desarreglo de la sensación.
\end{abstract}

\section{SUMMARY}

Deleuze's philosophy of art pays attention to the various ways in which the logic of representation is challenged. His analysis of certain artistic practices function as a critical apparatus of essentialism. It is interesting in this work to see how the prob-
Palabras clave:

Deleuze,

representación, sensación, cuerpo

Keywords:

Deleuze,

representation, sensation, body

Argentino. Profesor de grado universitario en Filosofía por la Universidad Nacional de Cuyo, Mendoza, Argentina. Becario doctoral de CONICET y docente de la Universidad de Congreso en la ciudad de Mendoza. Contacto: luisnicolasperrone@gmail.com ORCID: https://orcid.org/0000-0003-1979-4771 
lematization of corporeality is part of the Deleuzian effort to overcome representation. This translates into a particular logic of sensation, within which it is not possible to build closed strata or reduce them to identity forms. On the contrary, the sensation is incorrectly adjusted to the extent that forces circulate that act on the bodies and constantly transform them. To understand such deviation, we propose to analyze concepts such as "body without organs", "haecceity" and "becoming a minority", and to observe how some artistic practices make these notions operate within the framework of a derangement of sensation.

\section{RESUMO}

A filosofia da arte de Deleuze se concentra nos diversos modos em que a lógica da representação é rompida. Suas análises sobre certas práticas artísticas funcionam como um aparato crítico do essencialismo. Neste trabalho nos interessa ver como a problematização da corporalidade é parte do esforço deleuziano de superação da representação. Isto se traduz em uma lógica particular da sensação, dentro da qual não é possível construir estratos fechados nem reduzidos a formas identitárias. Pelo contrário, a sensação está desajustada na medida em que circulam forças que atuam sobre os corpos e os transformam constantemente. Para compreender tal desvio, nós nos propomos a analisar conceitos como corpo sem órgãos, hecceidade e devir-minoritário, e observar como algumas práticas artísticas fazem operar essas noções no contexto de uma desordem da sensação.
Palavras-chave:

Deleuze, representação, sensação, corpo 


\section{Introducción}

El pensamiento de Gilles Deleuze es abiertamente reacio a nociones de índole esencialista. A lo largo de su obra, son múltiples los desarrollos teóricos que realiza en virtud de la construcción de una nueva imagen del pensamiento, dentro de la cual se produzcan escapes de la lógica de la identidad. Asimismo, existe una constante preocupación del pensador respecto del problema de la corporalidad y los modos de subjetivación. Con esto queremos referir la resistencia de Deleuze a sostener una noción de "sujeto". Deleuze construye numerosos conceptos que muestran el carácter descentrado de la subjetividad y su imposibilidad de reducirla a una esencia. El esfuerzo del filósofo es el de superar la imagen dogmática del pensamiento, la cual tiene uno de sus ejes en la representación. De acuerdo con esto, los abordajes deleuzianos sobre la problemática del cuerpo están enfocados en la producción de conceptos que destaquen el constante carácter de movimiento que los mismos revisten y, a la vez, colaboren en la comprensión de su dimensión acontecimental. Asimismo, estas cuestiones tienen sus resonancias en la tematización de las artes, por lo cual la pregunta que nos motiva es ¿cómo opera la mediación del cuerpo en la construcción de la filosofía del arte deleuziana en relación con el problema de la representación? Si bien el problema es recurrente en los estudios sobre el autor, nos interesa enfocarlo desde la perspectiva de las artes como un modo de desajuste de la sensación, para así comprender la dimensión que se abre en el cruce de la imagen y el cuerpo. Cabe aclarar que empleamos la expresión "desajuste de la sensación" como un concepto y como una hipótesis. Tenemos en cuenta, para ello, que existe un desarreglo de los sentidos como una parte del programa estético deleuziano (Navarro Casabona 200). En virtud de ello, resulta pertinente pensar esa imagen de desarreglo en clave conceptual, pues es útil para comprender y articular la labor de Deleuze con relación a la estética, y entender las artes como aquello que producen desajustes en el régimen de la sensación.

Los trabajos que Deleuze dedica a la literatura, pintura, música, teatro o cine tienen la particularidad de no adherirse a los mismos parámetros con los que trabaja la filosofía del arte tradicional. Esto ha llevado a poner en discusión si realmente se puede hablar de una estética en el pensamiento del autor. Arnaud Villani apuntala esta dis- 
cusión a partir de las posturas de Merielle Buydens y Jacques Rancière. Villani cuestiona la lectura de Buydens, por circunscribir el pensamiento de Deleuze a una suerte de aformalismo, pues contrapone la noción de multiplicidad a la de forma, y coloca a esta última en un lugar secundario e, incluso, subsumido a la primera. Pero esto "denota un pensamiento del arte que no consiguió salirse de la representación" (Villani 86), por lo cual considera que la interpretación no es adecuada. De hecho, Villani replica que, en una correspondencia privada con Deleuze, él mismo rechazó esa postura. Por su parte, Rancière inscribe el proyecto deleuziano en un cumplimiento del destino de la estética y señala que éste produce un quiebre de la poética en tanto orden de la representación (Rancière 2002 208). Esto es comprensible desde la idea rancieriana de un régimen estético del arte, que refiere una distinción de los productos artísticos en un modo de ser sensible específico y heterogéneo (Rancière 2014 35). Si bien esto parece describir el proyecto deleuziano, las referencias del régimen estético del arte de Rancière no son las mismas que las de Deleuze; y, sobre todo, este último no plantea una consumación o fin del arte, sino que piensa en términos de experimentación estética. Para él, el reparto de lo sensible no es una mera distribución empírica heterogénea, sino que constituye formaciones en fuga, es acontecimental. Tal como señalan comentadores como Felipe Larrea, "para Deleuze lo sensible es, ante todo, asimétrico y diferencial, y no se posa sobre un sensible empírico" (Larrea 31), razón por la cual se hace necesario entender que lo sensible es producido por fuerzas. Es desde aquí, entonces, que nos interesa pensar el desajuste de la sensación en la estética deleuziana, siempre y cuando no entendamos por estética un régimen de conceptos que se empleen para interpretar las prácticas artísticas, sino una imagen del pensamiento en la que se elucida el influjo de las fuerzas sobre los cuerpos. Desde este punto de vista, es posible mantener el término y analizar el desajuste de la sensación a partir del cuerpo y del modo en que las artes, tal como las aborda Deleuze, contribuyen a ello.

Las reflexiones estéticas de Deleuze no son ajenas al problema de la representación. De hecho, los abordajes del filósofo acerca de la cuestión artística no están dirigidos meramente a un análisis de las obras en sí, sino a considerar el modo en que éstas irrumpen como una modalidad desnormalizadora, tanto del pensar como de la sensación. 
Como mencionamos, la crítica deleuziana sobre la imagen dogmática del pensamiento tiene su eje en el esfuerzo por correrse de la noción de representación. Esta preocupación puede observarse desde sus primeras obras. Por ejemplo, en Nietzsche y la filosofía Deleuze muestra que el problema de la imagen dogmática reside en la consideración de la verdad como un universal abstracto en detrimento de su carácter plural de circulación de fuerzas; cuando, en realidad, es a través de ellas que aparece el sentido como un elemento más radical del pensamiento (Deleuze 1998 146-148). Así, el acto de creación es el que da al pensamiento un nuevo lugar. François Zourabichvilli ${ }^{1}$ señala que esto no confina el pensamiento a un mero subjetivismo, sino más bien desajusta tal noción y coloca el pensar fuera de sí, permitiendo una nueva imagen del mismo (28).

Con la intención de comprender esta postura, nuestro trabajo pretende abordar el vínculo entre artes y corporalidad, con el fin de hacer presente una cartografía que nos permita pensar la noción de "desajuste de la sensación". Para ello, consideramos pertinente, por un lado, analizar ciertos conceptos que habilitan un pensamiento sobre la corporalidad crítico del esencialismo, tales como "cuerpo sin órganos" y "haecceidad". Asimismo, haremos alusión a la noción de "devenir minoritario", pues en ella se evidencia la vinculación política que conlleva el problema de la corporalidad, la cual es inescindible del trabajo deleuziano sobre la estética. Por otra parte, la consideración de estos conceptos nos lleva a inscribir la filosofía del arte deleuziana en el marco de un proyecto de desajuste de la sensación, en el sentido de una lógica de flujos de fuerza que conducen a la aisthesis hacia un

1 Zourabichvilli explica que la crítica deleuziana a la imagen dogmática del pensamiento se realiza en tres grandes aspectos: querer, reconocer, fundar. En cuanto al primero, el pensar y el pensador se encuentran en una relación de afinidad con lo que quieren conocer, la verdad, por lo cual la dan por supuesto. Así, se establece una voluntad de verdad, de querer lo verdadero. Asimismo, esta voluntad de verdad es un reconocer; si lo verdadero ya está allí para que el sujeto lo reconozca, esto significa que el sujeto se lo representa y que el objeto adquiere caracteres de homogeneidad e identidad. Por último, el pensamiento dogmático se ha dedicado a la empresa constante de búsqueda e instauración de un fundamento. Esto presupone una unidad y totalidad del mundo que se representa en esa noción de origen. Por lo tanto, en realidad la filosofía no deja de lado los presupuestos, aun en sus intentos de fundación. La nueva imagen del pensamiento, en cambio, rompe estas estructuras en virtud de un realce de lo heterogéneo y la multiplicidad, y se lanza a un devenir activo de las fuerzas del pensamiento (Zourabichvilli 16-28 y Deleuze 1998 146). 
territorio irreductible a identidades fijas. Con vistas a demostrar este último punto, tomamos en consideración algunos casos provenientes del teatro, la danza, la imagen cinematográfica, la poesía y la pintura, como un modo de vislumbrar en prácticas específicas la operación de los conceptos deleuzianos que contribuyen a producir un desajuste de la sensación.

\section{Tres claves de una corporalidad desnormalizada}

\section{a. Del cuerpo sin órganos}

En el trabajo que realizan "a cuatro manos" Gilles Deleuze y Félix Guattari, en El Antiedipo y Mil mesetas, una de las nociones que transita los textos y adquiere gran relevancia es la de "cuerpo sin órganos" (CsO). Este concepto, en principio, está tomado en préstamo de Antonin Artaud y se presenta como una crítica a la concepción del cuerpo como organismo, a la reducción de aquel a una entidad unitaria. No obstante, Eric Alliez (103) destaca que Deleuze se remite también a D. H. Lawrence para formular el CsO como una vitalidad no orgánica, pues el escritor inglés presenta constantemente cuerpos defectuosos que cuestionan la organización hegemónica de los mismos. Esto es importante para comprender que el cuerpo da cuenta de una relación con fuerzas y potencias imperceptibles que, finalmente, terminan apoderándose de él (Deleuze 1996 207). Dicho esto, queda claro que el CsO se enfrenta a la organización. "El enemigo es el organismo. El CsO no se opone a los órganos, sino a esa organización de los órganos que llamamos organismo" (Deleuze y Guattari 2010b 163). Esta manera de comprender el cuerpo aparece como una alternativa de apertura y entrecruzamiento de multiplicidades, que impiden aprehenderlo de forma clausurada en la figura de una definición. Asimismo, permite desustancializarlo y no hacerlo caer en el caos sin más. El esfuerzo, entonces, se centra en pensar por fuera del binarismo uno-múltiple, orden-caos. El cuerpo es territorialización al paso. Es una meseta que puede configurarse de múltiples formas y que puede evitar la sujeción que supone el organismo. Respecto de esto, Deleuze expresa:

Aquí está lo que hay que comprender: la onda recorre el cuerpo; en tal nivel se determinará un órgano, según la fuerza encontrada, y este órgano cambiará, si cambia la propia fuerza, o si se pasa a 
otro nivel. En pocas palabras, el cuerpo sin órganos no se define por la ausencia de órganos, no se define solamente por la ausencia de un órgano indeterminado, se define finalmente por la presencia temporal y provisional de órganos determinados (Deleuze 2009 54).

Los órganos en sí mismos no constituyen un problema que haya que extirpar, sino que, más bien, lo que se torna conflictivo es su fijación y endurecimiento, de tal forma que impidan la aparición de otras posibilidades de existencia. Por ello, se puede decir que el cuerpo sin órganos es intensivo, es el territorio por el que circulan diversas fuerzas que experimentan distintas intensidades. Lo que hay es una gradualidad de flujos en tránsito y no un espacio fijo que funcione de soporte a la representación de un organismo. Lo que falta no son órganos; estos, más bien, adquieren distintas funciones que se alteran en la medida en que las fuerzas intensivas que los determinan también cambian. Cada tipo de CsO implica modos heterogéneos de producción que se suceden sobre un plano. Así, pues, la manera de hacerse el cuerpo es a través de la experimentación, ya que ella permite explorar diversas alternativas, hacer circular flujos, establecer conexiones inesperadas, liberar líneas de fuga.

Ahora bien, Deleuze y Guattari aclaran que dicha experimentación no tiene que ver con la destrucción del propio cuerpo. "Deshacer el organismo nunca ha sido matarse, sino abrir el cuerpo a conexiones que suponen todo un agenciamiento, circuitos, conjunciones, niveles y umbrales, pasos y distribuciones de intensidad, territorios y desterritorializaciones" (Deleuze y Guattari 2010b 164-165). La paradoja, por ejemplo, de un cuerpo masoquista, catatonizado o intoxicado, es que se ha librado de la organización de los órganos a través del vaciamiento de órganos. Deshacer la organización es desterritorializarla, pero aniquilarse resulta impotente en tanto no permite nuevos agenciamientos, nuevas formas de circulación y acoplamiento.

Resulta importante señalar que esta forma de pensar el cuerpo desorganizado conlleva una separación de la fenomenología, por cuanto no hay una coincidencia entre el cuerpo y el mundo. Alain Beaulieu (43-45) repara muy bien en este aspecto al afirmar que tal coincidencia implica un intento de recuperar la trascendencia, y reduce el cuerpo a una experiencia ordenada y jerarquizada, la cual desconoce el influjo 
de las fuerzas sobre el CsO. En cambio, "lo que importa es dar cuenta de las fuerzas de una vida anorgánica que proviene de un Afuera y atraviesan el cuerpo, escapando de la experiencia vivida" (Id. 44). El CsO se localiza en la materia; pero no se reduce a ella, dado que el tejido de fuerzas produce zonas de intensidad. Por ello, no está limitado por la mera extensión. Este es un claro indicio sobre el desajuste de la sensación que engendra a partir del concepto de CsO.

Según lo expuesto, podemos comprender que el CsO se emparenta con otro concepto clave que opera en la filosofía de Deleuze y Guattari: el de "máquina deseante". En El Antiedipo, los pensadores explican que el deseo funciona como una máquina, ya que es productivo y no la positividad de una carencia. En este sentido, la máquina aparece como un sistema de cortes y flujos, de conexión con otras máquinas. "El deseo no cesa de efectuar el acoplamiento de flujos continuos y de objetos parciales esencialmente fragmentarios y fragmentados. El deseo hace fluir, fluye y corta" (Deleuze y Guattari 2010a 10). Este régimen de funcionamiento hace que la máquina trabaje de manera descompuesta, desarreglada. Su propiedad es maquinar fragmentariamente, extendiéndose en la interconexión de elementos. Lo que hay es actividad presente, exceso, fuerzas que circulan y se distribuyen permanentemente en todas direcciones; no hay representaciones fantasmáticas (al menos no como una pretendida esencia del deseo), sino producción, relaciones y movimiento.

El sistema productivo de flujos y cortes es el lugar donde se inserta el CsO como un modo de registro de la producción maquínica deseante. Pero ese registro es provisorio y no está sujeto a una identidad, sino abierto a múltiples conexiones, desajustes, desterritorializaciones. Por ello, los autores afirman que "el cuerpo sin órganos no es el testimonio de una nada original, como tampoco es el resto de una totalidad perdida. Sobre todo, no es una proyección; no tiene nada que ver con el cuerpo propio, o con una imagen del cuerpo. Es el cuerpo sin imágenes" (Deleuze y Guattari 2010a 17). De esta manera, el CsO escapa a la forma de la representación. El cuerpo no aparece como una imagen fantasmática, porque la máquina es pura producción de deseo. Al estar el CsO inserto en esa producción, se vuelve improductivo, esto es, se torna una suerte de superficie en la que se registran los procesos deseantes. Lo que realmente hay son diversas síntesis, distintas formas de 
elaboración que movilizan energía a modo de conexión, de separación y de producción residual.

Podemos pensar un ejemplo de estas nociones en el trabajo experimental que lleva a cabo Jerzy Grotowsky en el teatro, a partir de la década de 1970, y que tiene enorme influjo en los desarrollos posteriores del teatro experimental en todo el mundo. A través de lo que el artista polaco llama "laboratorio", el director y los actores exploran diversas posibilidades del cuerpo y del texto que se desprenden de la representación naturalista y mimética en lo referente a la construcción del espectáculo teatral. En la visión de Grotowsky, el cuerpo es lo que constituye el núcleo fundamental del teatro; cualquier otro elemento (como vestuario, maquillaje, etc.) es prescindible. Ahora bien, sus investigaciones, influenciadas en gran medida por las ideas de Artaud, se encaminan a la búsqueda de una corporalidad no organizada de manera cotidiana, sino que más bien posibilite la exteriorización de impulsos y la conexión múltiple de elementos para la construcción de un cuerpo extracotidiano (Grotowsky 10-12). Así, por ejemplo, los actores pueden trabajar, de manera disociada, secuencias de movimientos, calidades de energía y modificaciones vocales. Todos esos elementos se combinan en una suerte de agenciamiento maquínico, que viene a inscribir el cuerpo sin órganos como su residuo. Es decir, la puesta en escena resulta de una serie de ejercicios pluriformes, que más tarde son conectados, agenciados en la producción del espectáculo. Esto reporta un modo nuevo de producción de la corporalidad, el cual se pone en la vereda opuesta de la representación y la mímesis, y hace circular una serie incontable de flujos asignificantes, los cuales, en todo caso, adquieren significación en la apropiación que el propio espectador puede realizar al consumarse el hecho teatral. De esta manera, el trabajo de Grotowsky muestra que la experimentación del actor sobre sí mismo reviste una producción deseante que cuaja en formas no representacionales de la actuación, lo cual está sumamente emparentado con la noción de "cuerpo sin órganos" y su resistencia a la organización jerárquica del organismo.

\section{b. De la haecceidad}

El concepto de "haecceidad" se emparenta con el de "cuerpo sin órganos". Con este concepto, inspirado en Duns Scotto y Gilbert Simondon, 
Deleuze intenta pensar un modo de individuación que no se halle reducido a una unidad sustancial, ni a un sustrato esencial, como tampoco a una forma universal y separada. Por el contrario, la haecceidad es una modalidad de intensidad. Tal como Deleuze explica en un diálogo con Claire Parnet, esto le permite elaborar un agenciamiento de multiplicidades, en un plano de consistencia o inmanencia, es decir, la constitución de un plano en el que se establecen "relaciones de movimiento y de reposo, de velocidad y de lentitud, entre elementos no formados, relativamente no formados, moléculas o partículas arrastradas por los flujos" (Deleuze y Parnet 104). Por lo tanto, los modos de individuación de las haecceidades se refieren a fuerzas de diversa índole, que se cruzan y acoplan.

Según esto, podemos observar una múltiple caracterización de la haecceidad. Por un lado, se refiere a un modo de individuación que no atañe simplemente al sujeto; por otro, refiere una cartografía de la corporalidad, y, finalmente, dicha individuación implica una etología de los afectos. Por supuesto que todos estos elementos están imbricados y su distinción es, más bien, analítica. Respecto del primer término, es interesante reparar en que las haecceidades vienen a formar parte de una imagen del pensamiento en la que no hay una diferencia entre sujetos constituidos y objetos o medios, sino que se integran en un mismo agenciamiento de multiplicidad.

Una estación, un invierno, un verano, una hora, una fecha, tienen una individualidad perfecta y que no carece de nada, aunque no se confunda con la de una cosa o un sujeto. Son haecceidades, en el sentido de que en ellas todo es relación de movimiento y de reposo entre moléculas o partículas, poder de afectar y ser afectado (Deleuze y Guattari 2010b 264).

De esta manera, hay modos de individuación o haecceidades de todo tipo, no exclusivamente en los sujetos; éstos, más bien, entran en agenciamientos que permiten hablar de formas de subjetivación no relacionadas con la identidad, sino, más bien, con el devenir. Las relaciones de movimiento y sus velocidades adquieren una importancia crucial. Así, por ejemplo, en la película Nazareno Cruz y lobo, dirigida por Leonardo Favio, hay una escena en la que los protagonistas corren por unos pastizales movidos violentamente por el viento. El efecto parece el de un oleaje de mar, de modo que se vuelve indiscernible la 
distinción entre lo líquido y lo sólido, entre la espesura y la liviandad. Los cuerpos se desestructuran; ya no corren, parece que nadan, nadan corriendo. Los sonidos de la noche y de los perros de caza se mezclan con la música, y los colores se vuelven de tonos azules inverosímiles. Hay una individuación sin sujeto; las hierbas hablan, devienen. Se produce, así, un devenir de multiplicidades, en el que encontramos la haecceidad tanto en la naturaleza, como en los cuerpos de los sujetos y hasta en el tiempo y espacio particular que se abre en el recorte que opera en la imagen. Todos estos elementos componen una haecceidad, en la que no se puede decir que uno esté dentro del otro, sino que hay agenciamientos de multiplicidades. Otro caso de esta índole podemos observarlo en una escena de Prénom Carmen, de Jean Luc Godard. El encuadre muestra el oleaje del mar y el sonido de tales olas se superpone al de la música. Luego vemos a los dos protagonistas hablando, pero no es posible oír sus voces, ya que los anteriores sonidos están por sobre ellas. Finalmente, oímos sus voces al mismo nivel que el mar, el cual no es nunca un sonido de fondo. Estas imágenes auditivas ponen en evidencia una interesante cartografía de haecceidades, al mismo tiempo que marcan el desarreglo sensorial respecto del sonido. Las individualidades de los sujetos, las voces, el mar y la música están interceptadas unas por otras, acopladas, y producen un plano de composición en el que no se reconocen identidades de manera puramente mimética.

Asimismo, las haecceidades se relacionan con un modo de cartografía del cuerpo. Deleuze emplea los conceptos de latitud y longitud para explicar estas características de la corporalidad. En diálogo con Claire Parnet explica que el cuerpo está constituido por coordenadas que implican partes extensivas y variaciones intensivas. "Una cosa, un animal, una persona, sólo se definen por movimientos y reposos, velocidades y lentitudes (longitud), por afectos, por intensidades (latitud)" (Deleuze y Parnet 105). La longitud de un cuerpo remite a la composición de sus partes, pero no a la manera de una mera sumatoria de elementos, sino como un campo material por el que circulan fuerzas en diversas relaciones de velocidad. La latitud, por su parte, refiere relaciones dinámicas de potencia, esto es, de flujos de intensidad, de capacidad de afectar y ser afectado. Como aporta Anne Sauvagnargues, las coordenadas de longitud y latitud "permiten considerar el cuerpo individuado como el resultado de un diagrama de fuerzas ejercidas 
efectivamente sobre él" (Sauvagnargues 119). Esto resulta de particular interés para reafirmar el esfuerzo constante de Deleuze por escapar al dualismo y a toda forma de esencialización del individuo, en virtud de la composición de un plano de inmanencia.

Si consideramos la corporalidad que se manifiesta en la danza butoh, podemos apreciar fácilmente estas coordenadas. El cuerpo que deviene en esta danza japonesa es un cuerpo alejado de la representación (Pérez Monjaraz). Es un cuerpo sin órganos, sin organización jerárquica. Su longitud aparece en las fuerzas que circulan en sus partes extensivas: generalmente disociadas, cada parte presenta diferentes relaciones de velocidad; a veces muy lentas, como en los dedos de una mano o los pies moviéndose en transiciones minúsculas, o en las rodillas y los brazos haciendo pequeñas torsiones; otras veces las velocidades aumentan, y el cuerpo cambia abruptamente su espacialización. Todo esto deja circular otras fuerzas, internas, que constituyen su latitud. El cuerpo se vuelve, así, intensivo; los flujos de energía interna lo hacen adquirir diversas calidades, como una densidad similar a la de la tierra, o una volatilidad como la del aire, o una vibración como la del fuego. Estos modos de abordaje y experimentación inorgánica del cuerpo, sumados a numerosos trabajos sobre gestos aberrantes, grotescos o extraños, producen una corporalidad fragmentada y asignificante por la que circulan flujos afectivos, y constituyen una intensidad del cuerpo que no se puede sustraer a ninguna forma de representación.

Por otra parte, como hemos señalado, la haecceidad implica un modo de circulación de afectos. Los cuerpos, en rigor, "no se definen por su género o por su especie, por sus órganos o sus funciones, sino por lo que pueden, por los afectos de que son capaces, tanto en pasión como en acción" (Deleuze y Parnet 70). La haecceidad pone de manifiesto los modos en que los cuerpos son afectados y afectan a otros. Esto configura un plano de inmanencia por el que circulan grados de fuerza, líneas que no son formas definitivas, sino puro devenir. Los cuerpos devienen porque son capaces de diversas afecciones que les permiten el contacto con lo distinto, lo anómalo, lo extraño; se relacionan con otros cuerpos, con otros medios, que van diagramando un campo, un plano, donde hay fuerzas y flujos circulando en diversos grados de intensidad. Por ello, para Deleuze, el análisis 
del cuerpo comporta una cierta etología de los afectos, es decir, un mapeo de las diversas afecciones de que se es capaz. En este sentido, las artes se constituyen como un ámbito privilegiado para el devenir afectivo. Sauvagnargues (139-142) repara muy bien en este aspecto. Las producciones artísticas territorializan los fenómenos afectivos en materias expresivas, lo cual les otorga un estatuto incuestionable de vitalidad. Los mismos Deleuze y Guattari (2013 164-165) subrayan la importancia de la composición artística como una actividad que construye bloques de sensación. Esto pone en contacto directo con los fenómenos vitales. Lo que las artes son capaces de crear son afectos y perceptos, esto es, sensaciones que se vuelven independientes de quien las experimenta y revisten, al mismo tiempo, un carácter epistémico. En este sentido, la creación artística no se limita a un mero sensualismo, pues sus construcciones adquieren una autonomía que, posibilitada por la creación de perceptos, abren su espectro hacia un pensamiento sensible.

Deleuze se esfuerza por pensar la corporalidad desde una lógica de la diferencia y del acontecimiento. El dinamismo y la cinemática de la haecceidad permiten construir una nueva imagen del pensamiento, que evite caer en reduccionismos y en subsunciones a un yo. La haecceidad no requiere de una forma para su definición, pero esto no implica que sea una pura indeterminación. Como afirma Sauvagnargues, “(...) la haecceidad no comporta la disolución del sujeto ni el desvanecimiento de las cosas, sino un cambio en su estatuto lógico, una rectificación epistemológica de su modo de existencia real" (125-126). Lo crucial en este modo de individuación son las fuerzas reales que implica, la materialidad que la compone, la cual, como el cuerpo sin órganos, no se identifica con una organización hegemónica.

\section{c. Del devenir minoritario}

En el marco de la crítica a la representación y a la unidad, que hemos visto a través de nociones como las de "cuerpo sin órganos" o "haecceidad", se inscribe la problemática política de Deleuze. La preocupación por la subsunción a la norma está en el eje de sus reflexiones. Por ello, el devenir adquiere una enorme importancia. El devenir, que funciona como una operación, es siempre del orden de lo minoritario y, en este sentido, 
hay un particular interés de Deleuze por él, ya que allí se manifiesta un modo divergente de comportamiento en relación con la normatividad.

El primer aspecto del devenir es su función de proceso y su alejamiento de cualquier tipo de teleología. No existe una pretensión de erigir una modalidad de subjetividad hacia la que haya que tender. Lo fundamental son los diversos tipos de agenciamientos que se producen, las conexiones, las alianzas, las desterritorializaciones. Un agenciamiento, en efecto, funciona como un modo de acoplamiento de elementos y de relaciones. En El Antiedipo, los autores expresan esta idea bajo la noción de "máquina deseante"; pero en Mil Mesetas la desplazan y hablan de "agenciamientos" para indicar el proceso conectivo de un encuentro. Desde este punto de vista, la importancia del devenir radica en el mismo acto de estar siendo, de producir alianzas y conexiones. Por lo tanto, la problemática tampoco se enfoca desde el acto de escoger entre diversas alternativas de ser, pues, en todo caso, éstas aparecen en la medida en que se producen los agenciamientos. Como afirman Deleuze y Guattari: "El devenir no produce otra cosa que sí mismo. Es una falsa alternativa la que nos hace decir: o bien se imita, o bien se es. Lo que es real es el propio devenir, y no los términos supuestamente fijos en los que se transformaría el que deviene" (Deleuze y Guattari 2010b 244).

De acuerdo con esto, podemos comprender el carácter minoritario de todo devenir. Al no haber un punto de origen ni de llegada, y mucho menos un centro a partir del cual se organice lo que deviene, es claro que los devenires no se pueden enmarcar dentro de una estructura mayor que los contenga, lo que los filósofos llaman "estructura molar" (Deleuze y Guattari 2010b 218). Esto permite cargarlos de una potencialidad inherente de resistencia a la norma. Así, pues, todo devenir es minoritario o molecular porque se ubica al margen de las instancias molares y permite la proliferación de singularidades. Ahora bien, aquí no hay que entender, de manera reduccionista, una mera oposición entre molar y molecular, mayor y menor. No son dos instancias aisladas entre sí. Cada una puede nacer en la otra, y cada una puede instalarse en la otra. El análisis micropolítico debe "intentar agenciar los procesos de singularización en el propio nivel en el cual emergen" (Guattari y Rolnik 185). No hay, por tanto, una oposición lógica (principio de no contradicción) entre lo mayor y lo menor. 
Tampoco es un problema de simple cantidad. De hecho, una minoría en número puede volverse molar. Lo importante es el estado de dominación que supone la constitución en una mayoría. Por ello, es necesario hacer la salvedad de que no es lícito identificar los procesos de minoración con la llana marginalidad. De alguna manera, lo marginal supone un estado pasivo al que se ha sido llevado por las regulaciones normativas que implican las mayorías. Los trabajos de Michel Foucault, por ejemplo, sobre la psiquiatría, la locura o las prisiones, han puesto de manifiesto la operación de control de la marginalidad que se suscita en las sociedades disciplinares. Lo que Deleuze y Guattari quieren explicar es que, si los devenires minoritarios se encuentran al margen de las formaciones sociales molares, es porque comportan una autonomía especial, que es, en último término, la que les permite erigirse como instancias de resistencia a las formaciones de poder. Los devenires minoritarios contribuyen a la desestabilización de esas formaciones. Son modos de desterritorialización.

Una modalidad de devenir a la que Deleuze y Guattari dan mucha importancia es el devenir mujer. Si, como sostienen, la problemática del devenir no se vincula con transformarse en otro, ni con la imitación, entonces este devenir mujer no puede pensarse desde el punto de vista de la defensa de una entidad molar llamada "mujer", esto es, una forma de feminidad primordial a la que haya que reivindicar. Aquí es necesario aclarar que Deleuze y Guattari no están suponiendo que haya que abandonar las luchas sociales que pretenden conquistas para todo un colectivo, ni tampoco que no sea necesario un modo de asociación política del colectivo molar mujer. Como ya hemos indicado, los devenires moleculares pueden instalarse en las instancias molares. Por lo tanto, las luchas feministas ancladas en problemáticas coyunturales no son descartadas. La propuesta se direcciona, más bien, hacia el agenciamiento de multiplicidades que puedan repercutir en modos de singularización no disciplinados por la norma molar. Por ejemplo, la normatividad que se desprende de la masculinidad hegemónica o del naturalismo corporal (mujer como cuerpo que engendra, entre otros) son algunos tipos de regulaciones que podrían desbaratar la fuerza revolucionaria del devenir mujer. En este sentido, Deleuze y Guattari son claros al afirmar que: 
Lo que nosotros llamamos aquí entidad molar es, por ejemplo, la mujer en tanto que está atrapada en una máquina dual que la opone al hombre, en tanto que está determinada por su forma, provista de órganos y de funciones, asignada como sujeto. Pues bien, devenir-mujer no es imitar esa entidad, ni siquiera transformarse en ella. (...) ni imitar ni adquirir la forma femenina, sino emitir partículas que entran en relación de movimiento y de reposo, o en la zona de entorno de una microfeminidad, es decir, producir en nosotros mismos una mujer molecular, crear la mujer molecular (Deleuze y Guattari 2010b 277).

De acuerdo con esto, el devenir mujer se vuelve paradigmático del carácter molecular de todo devenir. Si parece que los pensadores caen en un despojamiento de la historicidad de las mujeres, es porque están tratando de mostrar que no hay un sujeto subyacente, primordial y caracterizado por la mismidad, como ocurre en el pensamiento moderno, sino que, más bien, hay procesos de singularización, haecceidades, multiplicidades. Tampoco significa que haya un desarrollo lineal y temporal, ni que las mujeres deban asumir la bandera de todas las luchas. Como correctamente indica Paul Patton (121), este tipo de devenir es transhistórico, pone en evidencia la molecularidad de todos los devenires y, de esta manera, se sale del dualismo o de la oposición a un otro hegemónico en términos de luchas sociales. Si aún se persistiera en la definición de un grupo por oposición a su opresor, se estaría reduciendo la potencialidad revolucionaria y cercenando cualquier nueva configuración del devenir que pueda funcionar como anómala a la norma.

Así como el devenir mujer pone en evidencia el carácter molecular del devenir, el devenir animal también hace lo propio. Deleuze y Guattari prestan especial atención a este aspecto, pues explica muy bien el carácter marginal (en el sentido que ya hemos aclarado previamente) de la minoridad. Nuevamente, aquí tampoco es correcto creer que los filósofos están pensando algún tipo de relación imitativa con el animal. En realidad, el devenir animal pone sobre el tapete un modo heteróclito de circulación de flujos. En este sentido, la importancia de esta modalidad de devenir radica en la intensidad y en la afectología que supone. "Cada devenir-animal comportaba esa playa intensa, esa captura de afectos, esa desterritorialización que reterritorializa una 
nueva haecceidad y que es preciso considerar estrictamente en términos de velocidad y lentitud, de poderes de afectar y ser afectado" (Sauvagnargues 135). Este tipo de aproximación al animal es de índole molecular. Por ello, no hay ninguna fijación en cualquiera de los dos elementos, sino multiplicidades que circulan por el medio. Deleuze y Guattari lo indican explícitamente: "A los devenires-animales no hay que atribuirles una importancia exclusiva. Más bien serían segmentos que ocupan una región media" (Deleuze y Guattari 2010b 253). Esto es consecuente con la lógica rizomática con la que piensan los autores. No existen puntos de partida o de llegada, sino líneas que se tienden en múltiples direcciones por el medio. Un devenir siempre recorre velocidades y lentitudes por el medio; por ello, es molecular, ya que no se afirma en un sistema mayor que lo contenga y detenga su movimiento.

La problemática de los afectos en el devenir animal cobra especial concreción en las artes. Allí es posible el establecimiento de un plano de composición por el que circulen flujos afectivos de diversa índole e intensidad y, al mismo tiempo, que esos flujos puedan funcionar de manera experimental. En este sentido, las artes despliegan un plano vital, cuya inmanencia permite agenciamientos y desterritorializaciones particulares; esto es propicio para un desarrollo de modos de subjetivación que no estén subsumidos a formas de identidad y representación, sino que se emparenten con las formas del cuerpo sin órganos, la haecceidad y el devenir. Los fenómenos artísticos, con sus múltiples configuraciones, abren espacios de acceso a los afectos y a las intensidades; y su posibilidad de anomalía, como en el devenir animal, los inscribe en un plano de devenir minoritario, lo cual lo reviste de una potencialidad política de resistencia a la norma.
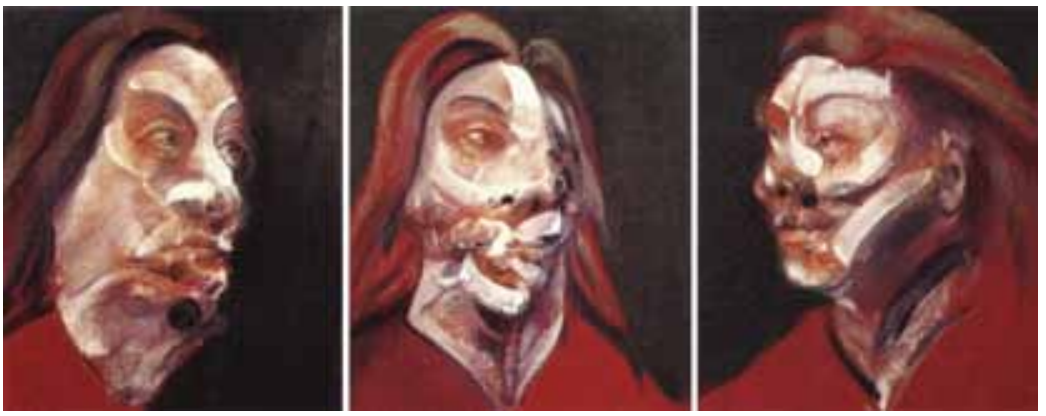

Figura 1. Bacon, Francis. Three studies of Isabel Rawsthorne. 1966 
El pintor Francis Bacon da cuenta de las relaciones de intensidad que suscita el devenir animal. Por ejemplo, en Tres estudios de Isabel Rawsthorne, de 1966, podemos ver el retrato de una mujer que está a medio camino entre el rostro femenino y el de una loba. El movimiento no se detiene en ninguno de los dos; es ambos, es el movimiento que hay entre ellos. La técnica del raspado y el barrido que emplea el pintor otorga una velocidad particular a esta pintura, e impide la fijación en cualquiera de los dos términos; ni mujer, ni loba; mujer y loba, devenir loba. No hay ninguna identidad. Hay, más bien, componentes que funcionan de forma sumativa, agenciamientos, fuerzas que se cruzan. No es posible aprehender la identidad de la imagen porque, como en todo devenir animal, los afectos que intervienen solo se pueden vivenciar en la experimentación misma. El devenir animal de la pintura abre nuevas dimensiones, lo cual es la piedra de toque de la concepción de la multiplicidad en Deleuze.

La poetisa Olga Orozco ahonda en las tensiones de la corporalidad y del devenir animal en su poema Entre perro y lobo. Los primeros versos anuncian un quejido sobre el cuerpo colonizado por el organismo: "Me clausuran en mí / Me dividen en dos / Me engendran cada día en la paciencia / y en un negro organismo que ruge como el mar" (Orozco 139). Aquí es claro el punto de contacto con la noción deleuziana de cuerpo sin órganos. Hay una resistencia a pensar el cuerpo como una organización cerrada, la cual no hace más que clausurar la propia subjetividad. A partir de allí, las imágenes a las que apela Orozco se emparentan con la animalidad, con lo bestial: lomo, sangre, colmillos, dentelladas, acto de devorar o de roer; todas ellas son formas del proceso de un cuerpo que no se detiene en su movimiento, que nunca está completo y que no tiende hacia una finalidad última. Esto le permite el flujo de un devenir que huya de las formas fijas y clausuradas. "Cambio bajo mi piel de perro a lobo / Yo decreto la peste y atravieso con mis flancos en llamas las planicies del porvenir y del pasado" (Ibíd.). La anomalía de lo animal contribuye a la configuración de un plano de composición en el que habite la multiplicidad. De este modo, el devenir se vuelve proceso de resistencia a los embates disciplinadores de la norma mayor, y es claramente molecular, en tanto que pequeñas partes se ponen en contacto con lo animal y bestial, y no permiten que el cuerpo cuaje en una forma definitiva y cerrada. 
El devenir minoritario, en suma, es el modo privilegiado en que se manifiesta la fuerza revolucionaria, pues huye incesantemente de las formas normativizadas. Las obras de arte menor, objeto de gran interés para Deleuze, son aquellas que permiten el cruce de líneas de diversa naturaleza y, en consecuencia, la fuga hacia terrenos anómalos que se resisten a la norma mayor. Estos modos de circulación de fuerzas e intensidades constituyen el carácter verdaderamente creativo de la obra artística y descubren su dimensión política inherente. Al mismo tiempo, muestran su aspecto de vitalidad, en la medida que no se pueden reducir a la imitación o representación y, por lo tanto, son fruto de una determinada experimentación; todo lo cual deja en evidencia la índole de proceso, de devenir, de acontecimiento y de antiteleología de las obras de arte.

\section{Las artes y su lógica de la sensación}

El pensamiento estético de Deleuze, como hemos visto, se mueve en una lógica que desarticula las formas fijistas. La obra artística hace circular flujos afectivos, y la intercesión del cuerpo es crucial para entender esta apuesta. La imagen, en la obra artística, es el territorio por el que pasan y se cruzan fuerzas, y, por ello, se relaciona con la corporalidad. Según esto, es claro que el ser de sensación que producen las artes no tiene que ver con el mundo de la representación ni se puede reducir a formas de identidad. Al colocarse al margen de la noción de imagen como esencia o sustancia, las visibilidades están atravesadas por fuerzas y potencias que las llevan a un mundo de acontecimientos, y esto impide la fijación en estructuras universales.

En ¿Qué es la filosofía? Deleuze y Guattari muestran que la obra de arte se conserva independiente de quien la produce. Esto pareciese otorgarle una relativa sustancialidad a la obra, pero, en realidad, la está liberando de cualquier modelo o de su identificación con su productor. Por ello, afirman que lo que se conserva es un bloque de sensaciones, esto es, un compuesto de perceptos y afectos. "Los perceptos ya no son percepciones, son independientes de un estado de quienes las experimentan; los afectos ya no son sentimientos o afecciones, desbordan la fuerza de aquellos que pasan por ellos" (Deleuze y Guattari 2013 164-165). Aquí es claro que los bloques de sensación exceden la vivencia; esto nos está mostrando un desarreglo de 
los sentidos, según el cual no es posible identificar o esencializar los perceptos y afectos; ellos, más bien, entran en un flujo de devenir que va en consonancia con esta lógica deleuziana de la no representación. Aquí nos encontramos, por lo tanto, con una consideración no referencial de la sensación; esta jamás remite a un objeto ni se identifica con un sujeto. Precisamente, como no existe un sujeto como identidad es que puede considerarse que los bloques de sensación exceden a quien los experimenta.

Deleuze despersonaliza la sensación. La práctica del artista desborda los estados perceptivos que se asocien a una mera vivencia. De allí que la obra artística no pretenda expresar o representar sentimientos, y mucho menos lograr la mímesis. Según esto, las prácticas artísticas desdibujan los límites de la figuración. Las artes se instalan en una zona de indiscernibilidad que libera la sensación de las estratificaciones y la identificación con formas acabadas, como si se tratara de la desorganización del organismo operada por el cuerpo sin órganos. Si tomamos por caso las figuras de los cuadros de Francis Bacon, es evidente que no nos hallamos ante la representación de un cuerpo, sino frente a la presencia de fuerzas y a la circulación de intensidades por un cuerpo sin órganos. Por ejemplo, en Tres figuras en una habitación, un tríptico de 1964, Bacon remarca la deformación de los cuerpos al punto de que la contorsión y la inverosimilitud de las poses logran manifestar un flujo de fuerzas que no se asocia tanto con un estado psíquico cuanto con un caos material del cuerpo. Figuras aisladas en un espacio pictórico construido por un círculo, apoyado un cuerpo sobre un inodoro, otro sobre un sillón y el último sobre una silla; esta economía de elementos hace concentrar la atención en los cuerpos que presentan un atletismo imposible, desproporcionado, sin huesos que los estructuren. Aquí podemos ver cómo la imagen y la corporalidad desajustan la sensación en la medida en que la separan de la lógica de la representación y, por ello, de la organización jerárquica del organismo. Según esto, la conservación independiente de un bloque de sensación no tiene que ver, como ya dijimos, con su sustancialidad, sino todo lo contrario. "Que el artista consiga que se sostenga en pie por sí mismo es lo más difícil. Se requiere a veces una gran dosis de inverosimilitud geométrica, de imperfección física, de anomalía orgánica" (Deleuze y Guattari 2013 165). 

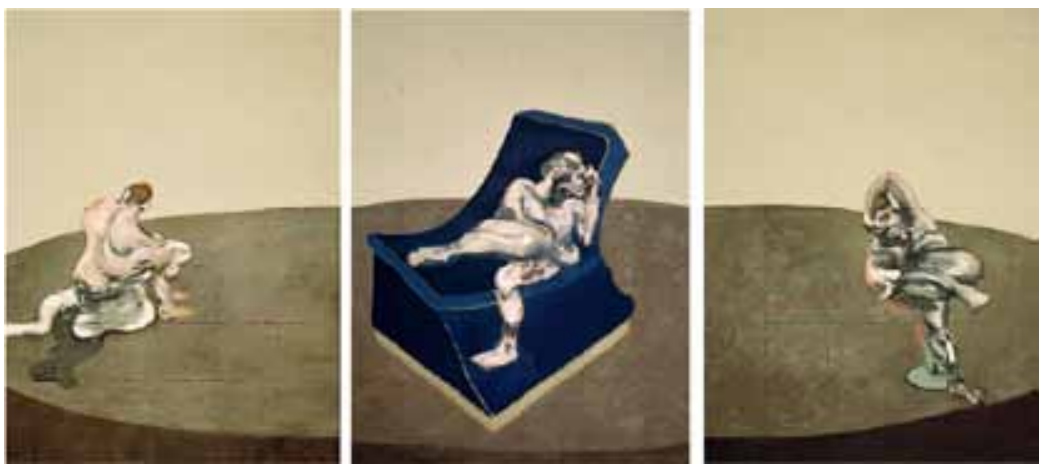

Figura 2. Bacon, Francis. Three figures in a room. 1964

La sensación se desterritorializa, desarma el sistema de la percepción dominada socialmente. Este desarme, a su vez, se reterritorializa en un plano de composición. Pero ¿cómo ocurre todo esto? Las sensaciones compuestas de perceptos y afectos no representan un mundo, sino que crean un espacio, un plano estético. Aquí Deleuze y Guattari muestran que ese plano estético creado no se reduce necesariamente a un constructo técnico; en todo caso, la técnica queda incluida en ese plano de circulación de la sensación, como una singularidad de la obra. Esto es interesante, por cuanto permite ver que la sensación produce un desajuste también en el nivel de los materiales. De acuerdo con los autores, "la sensación ya no se realiza en los materiales, más bien los materiales penetran en la sensación” (Deleuze y Guattari 2013 196). La sensación no es aquello que meramente se expresa a través del canal de los materiales y de la técnica, sino que ellos mismos devienen expresivos en un plano donde aparecen, como nuevas visibilidades, fuerzas de índole invisible. En este sentido, la sensación se extiende a lo largo de todo el plano compositivo abriendo visibilidades.

Por otro lado, resulta interesante ver cómo este desajuste de la sensación se comprende desde el punto de vista del concepto de "diagrama". En Francis Bacon. Lógica de la sensación, Deleuze trabaja esta noción para mostrar la importancia de la intromisión del caos en la composición de la pintura y, por tanto, en el desajuste de la sensación. En primera instancia, explica que "el diagrama es el conjunto operatorio de líneas y de zonas, de trazos y de manchas asignificantes y no representativos" (Deleuze 2009 103). En otros términos, el diagrama es 
una suerte de germen de posibilidades. A través de esta acción, la operación artística va materializando lo que luego constituirá la figura. Esto quiere decir que la composición pictórica (aunque creemos que esto bien es extensible a otras artes) no comienza siendo figurativa, es decir, su germen no se encuentra en el intento de representar una imagen, concebida previamente y de manera mimética. Más bien, el caos se encuentra en el principio del movimiento de creación, y su tratamiento deviene hacia la materialización de lo que, en una consideración corriente, podemos entender como una obra acabada. En realidad, la obra nunca es acabada, al menos no en términos teleológicos, teniendo en cuenta que los trazos que la originan son siempre asignificantes; por ello, no cuaja en un resultado significante final. De este modo, el diagrama muestra que la obra artística, o la pintura en este caso, no es figurativa. En los cursos de 1981 Deleuze realza el énfasis en este último aspecto y explica que el hecho pictórico prescinde de cualquier intención narrativa; y, por extensión, también lo hace cualquiera de las artes que se inscriban en una lógica de la sensación. "Suprimir la narración y la ilustración. Ese sería el rol del diagrama y del caos-catástrofe. Y, por tanto, suprimir todos los datos figurativos, pues las figuraciones y las narraciones están dadas, son datos" (Deleuze 2007 66). La lucha, por consiguiente, es contra el cliché, pues denota una representación dada de antemano.

Si bien la catástrofe funciona como germen de la pintura, esto no quiere decir que se reduzca a eso. El diagrama hace surgir algo de ese caos. Ese algo es la figura ${ }^{2}$. Evidentemente dicha figura no es ya figurativa, debido a que el diagrama ha desajustado todo intento de semejanza. En todo caso, es una especie de residuo de la actividad caótica que da lugar al acto de creación. Como apunta Alain Beaulieu (61), el partido por lo figural denota un medio de expresión de la presencia configurada por un tejido de fuerzas. Esto es fundamental

2 Deleuze muestra que existen tres posicionamientos diagramáticos. El primero corresponde a la abstracción (Vassily Kandinsky, entre otros), en el que el diagrama adquiere el aspecto de un código simbólico complejo. El segundo es el del expresionismo abstracto (Jackson Pollock, por ejemplo), dentro del cual el diagrama no está codificado, sino que se extiende a lo largo de todo el lienzo. Finalmente, se encuentra el arte figural, en el que el diagrama no invade todo el cuadro, sino que está localizado y hace surgir una figura no figurativa. Aquí piensa Deleuze la pintura de Francis Bacon (Deleuze 2009 103-112). 
para entender cómo, en las artes pictóricas — pero, insistimos, más allá de ellas-, se desarma el edificio de la representación. La sensación, entonces, se encuentra en una relación de desajuste, pues las fuerzas que la atraviesan ponen en crisis toda posibilidad de semejanza, de homogeneidad, de mímesis. Por lo tanto, la imagen debe ser entendida aquí como presencia, esto es, imagen sin semejanza, imagen que no imita. Esta imagen presencia tiene el poder de desnormalizar los sentidos.

Cuando Bacon habla de la sensación, quiere decir dos cosas (...). Negativamente, dice que la forma referida a la sensación (figura) es lo contrario de la forma referida a un objeto que se supone representar (figuración). (...) Y, positivamente, Bacon no deja de decir que la sensación es lo que pasa de un orden a otro. Por eso la sensación es maestra de deformaciones, agente de deformaciones del cuerpo (Deleuze 2009 43).

La obra de Bacon hace presente la sensación como intensidad y esto repercute en una corporalidad desnormalizada. El atletismo y la deformación de las figuras baconianas son claras muestras de que el organismo queda desarmado en sus funciones de organización jerárquica, pues es atravesado por diversos niveles de intensidad. Esto quita integración a los sentidos, dejando al descubierto una nueva visibilidad, una resonancia de múltiples sensaciones. No hay mímesis o copia de la apariencia sensible, sino instalación de fuerzas que antes no eran visibles. El cuerpo sin órganos es el residuo de ese recorrido sensible.

Finalmente, es interesante reparar en el hecho de que la función del diagrama en relación con el desajuste de la sensación se ve, además, en el desplazamiento de la jerarquía del sentido de la vista hacia el sentido del tacto y la tensión entre ambos. En efecto, Deleuze cree que lo diagramático en la obra de Bacon pone de relieve la función de una mano liberada del ojo en la operación pictórica. Las coordenadas visuales son desbaratadas por la intromisión de un caos manual, que violenta la organización de los trazos y manchas a partir del sentido de la vista, en virtud de la insubordinación de lo manual. Esto no quiere decir que lo óptico simplemente se subsuma a lo táctil. En realidad, la vista descubre una función táctil que le es propia. Es lo que Deleuze denomina función háptica del ojo (Deleuze 2009 158). Es una tensión 
en la que las fuerzas hacen presente la figura como un cuerpo sin órganos. Las variaciones de colores reafirman el carácter de superficie de la pintura y permiten al ojo una suerte de tacto, un tocar que no es meramente manual, pero definitivamente es la no supeditación a la organización esencializante del ojo. Lo que aparece como imagen es una presencia, la figura como emergente del diagrama, el situarse en medio de los devenires para presentar las fuerzas que actúan sobre los cuerpos. Nada se reduce al caos, éste es un mero germen. Pero nada, tampoco, queda apresado por la semejanza.

En suma, el concepto de "diagrama" le sirve a Deleuze para explicar la operación que se efectúa en la pintura, a efecto de habilitar las posibilidades para que surja lo figural en sentido no representativo. Esto muestra un desajuste de la sensación, en la medida en que ésta no se halla organizada, no se reduce a la aprehensión óptica, no se identifica con un sujeto y no representa nada a priori; el desajuste hace visibles fuerzas que no lo eran. Es decir, lo pintado es la sensación misma. Esto es lo que logra la obra pictórica de Bacon.

\section{Conclusión}

Cuerpo e imagen configuran una cartografía particular, en la que la sensación se halla desajustada. A lo largo de nuestro trabajo hemos visto algunas modalidades en que esto se manifiesta. En primer lugar, los conceptos de "cuerpo sin órganos" y "haecceidad" dejan en evidencia que no es posible sostener una noción de corporalidad ligada a la representación y la identidad. Por el contrario, el cuerpo aparece como un conjunto en el que se agencian diversos elementos, y este modula heterogeneidades produciendo una ruptura con cualquier forma de esencialismo. Esto permite desajustar la noción de "corporalidad" y abrirla hacia un territorio que deshace la representación. Algunos ejemplos de obras artísticas mencionadas, tales como el teatro físico de Grotowsky, la danza butoh, la pintura de Bacon o el cine de Godard, dan también cuenta de ello. Según esto, es posible pensar la imagen como presencia y no como mímesis, lo cual nos permite afirmar que el proyecto estético deleuziano se inscribe en la crítica de la lógica de la identidad, quebrando la noción de "imagen como semejanza". Por otra parte, la problemática del cuerpo no se halla disociada de ciertas implicancias políticas. En este sentido, 
vimos que a través del concepto de "devenir minoritario" se abre un campo de reflexión sobre las posibilidades desnormalizadoras de la corporalidad. Esto no es ajeno a las artes en la medida en que producen imágenes como presencias, las cuales pueden desestructurar el sistema de lo socialmente regulado. Todo esto nos muestra que la sensación con la que trabaja la obra de arte se encuentra desajustada, pues quiebra las formas perceptivas usuales. El sistema de lo sensible en la lógica deleuziana se configura en planos de composición por los que circulan fuerzas de intensidades diversas, impidiendo que el recorte de lo sensible quede anquilosado en formas definitivas y mucho menos jerárquicas. En este sentido, la lógica de la sensación produce cuerpos sin órganos, ya que no existen organizaciones estratificadas de manera absoluta. Por lo tanto, es posible pensar algunas prácticas artísticas contemporáneas en una cartografía en la que los elementos estéticos, corporales y políticos juegan roles indisociables, y muestran como efecto que existe un desajuste de la sensación, que permite pensar nuevas modulaciones de la corporalidad y de la imagen más allá de la semejanza.

\section{Bibliografía}

Alliez, Eric. "La condición CsO o de la política de la sensación". Revista Laguna 15 (2004): 91-106.

Beaulieu, Alain. Cuerpo y acontecimiento. La estética de Gilles Deleuze. Buenos Aires: Letra Viva, 2012.

Deleuze, Gilles. Crítica y Clínica. Barcelona: Anagrama, 1996.

Deleuze, Gilles. Nietzsche y la filosofía. Barcelona: Anagrama, 1998.

Deleuze, Gilles. Pintura. El concepto de diagrama. Buenos Aires: Cactus, 2007.

Deleuze, Gilles. Francis Bacon. Lógica de la sensación. Madrid: Arena, 2009.

Deleuze, Gilles y Guattari, Félix. El Antiedipo. Capitalismo y esquizofrenia. Buenos Aires: Paidos, 2010a.

Deleuze, Gilles y Guattari, Félix. Mil mesetas. Capitalismo y esquizofrenia. Valencia: Pre-textos, 2010b.

Deleuze, Gilles y Guattari, Félix. ¿Qué es la filosofía? Barcelona: Anagrama, 2013.

Deleuze, Gilles y Parnet, Claire. Diálogos. Valencia: Pre-Textos, 2013. 
Guattari, Félix y Rolnik, Suely. Micropolítica. Cartografías del deseo. Buenos Aires: Tinta Limón, 2013.

Grotowsky, Jerzy. Hacia un teatro pobre. México DF: Siglo XXI, 2006.

Larrea, Felipe. "Una estética deleuziana: génesis, figura y modulación”. Aisthesis 32 (2017): 29-47.

Navarro Casabona, Alberto. Introducción al pensamiento estético de Gilles Deleuze. Valencia: Tirant Lo Blanch, 2001.

Orozco, Olga. Poesía completa. Buenos Aires: Adriana Hidalgo editora, 2013.

Patton, Paul. Deleuze y lo político. Buenos Aires: Prometeo, 2013.

Pérez Monjaraz, Nayeli. "La desterritorialización del cuerpo. Una reflexión sobre la danza butoh". Reflexiones Marginales 36 (2016).

Rancière, Jacques. El reparto de lo sensible. Estética y política. Buenos Aires: Prometeo, 2014.

Rancière, Jacques. “¿Existe una estética deleuziana?”. Gilles Deleuze. Una vida filosófica. Ed. Eric Alliez. Medellín: Revista Euphorion, 2002. 205-211.

Sauvagnargues, Anne. Deleuze. Del animal al arte. Buenos Aires: Amorrortu, 2006.

Villani, Arnaud. “De la estética a la estésica. Deleuze y la cuestión del arte". Gilles Deleuze y su herencia filosófica. Ed. Alain Beaulieu. Madrid: Campo de Ideas, 2007. 81-97.

Zourabichvilli, François. Deleuze. Una filosofía del acontecimiento. Buenos Aires: Amorrortu, 2011. 